\title{
PI and Fuzzy Logic Controller based Comparative Analysis of Separately Excited DC Motor
}

\author{
Mohsin Ali Koondhar a,", Irfan Ali Channa ${ }^{\mathrm{b}}$, Syed Abid Ali Shah Bukhari ${ }^{\mathrm{c}}$, Muhammad Ismail Jamali ${ }^{\mathrm{a}}$, \\ Sadullah Chandio ${ }^{\text {a }}$, Ahsan Ali Memon ${ }^{\text {a }}$ \\ ${ }^{a}$ Department of Electrical Engineering, Quaid-e-Awam University of Engineering, Science and \\ Technology Nawabshah \\ ${ }^{\mathrm{b}}$ Department of Automation, Beijing University of Chemical Technology, Beijing, China \\ ${ }^{c}$ Department of Electrical Engineering, Quaid-e-Awam University College of Engineering, Science and \\ Technology Larkana \\ "Corresponding Author: engr.mohsinkoondhar@quest.edu.pk
}

\begin{abstract}
Separately excited de motors (SEDCM) are generally used in laboratory and industrial applications due to their high efficiency, performance response and high torque. An idea is proposed in this paper by applying the PI and Fuzzy Logic Controller (FLC) to control the speed of SEDCM. Simulink model with and without PI and FLC has been developed in Matlab to analyze the performance of de motor. Based on simulation results it is said that control characteristics of FLC are better than the conventional PI controller. The modeling of SEDCM and execution of the controllers is carried out in MATLAB.
\end{abstract}

Keywords- SEDCM; PI; Fuzzy Logic; MATLAB

Date Received: $09-10-2020$

Date Accepted: $31-10-2020$

Date Published: 08-06-2021

\section{INTRODUCTION}

$\mathrm{D}_{\mathrm{m}}^{\mathrm{C}}$ $\mathrm{C}$ motor is one of the usual motors that were put on the market at the end of the nineteenth century. Compared to other motors like induction motors [1-3], brushless dc motors [4], dc motors have domestic compensation like simple control high electromagnetic torque and speed are widely adjustable. Due to industrial applications dc motor used in mining, transportation, national defense, steel rolling [5].

Due to reasonable cost and the complexity of lower speed and torque control $[6,7]$ control configuration, dc motors are frequently used in many applications. DC motors are applied for various ower converters. There are various converters required to operate DC motor. It can be used for high torque loads, as well as the response to high acceleration and deceleration to the load [8].

DC motors are not so complicated; they only need to convert ac to dc power once. DC motors must convert electrical into mechanical energy called rotation. So torque relationships of dc motors are higher than AC motors [9].

The main objective of this research is discussed as

- To control speed by the help of PI.

- To control speed by using fuzzy logic controller

- To comparing both controllers and analysis of their performance of DC Motor.

\section{DC MOTOR AND DIFFERENT CONTROLLERS}

Motors can be divided into AC motors and DC motors. According to the excitation type and connection type, the dc motor between them can also be divided into two groups. that all appropriate references are included.

\section{A. Proportional Integral (PI) Controller}

PI can be applied to remove the steady state error and to optimized the speed response of motor [10-13]. By selecting different intellectual properties to gain the required speed of DC Motor [14].

Six-decades ago, compared with PID controllers, PI controllers with DC motors were widely used [15]. The output of the PI controller is used as a transformer adjustment indicator, but its output will provide a steady state response to the motor speed for dc motor and is close to the reference value $[16,17]$.

\section{B. Fuzzy Logic Controller}

The control unit is used to modify the behavior of the system to operate in a specific and ideal way over time. One of these controls is the fuzzy logic controller [18]. Due to uncertainty, using traditional methods to analyze and monitor complex, non-linear, and/or variable systems over time is a difficult task [19].

FLC uses the console to apply a series of unclear rules, relying on the communication between input data and output data. These rules include linguistic variables rather than complex mathematical models of the system. The main part of the mysterious console is the database, which is preceded by entries that translate errors and change the errors to language 
form. The successful part turns the language supervisor into an exit signal [20].

\section{RESULT AND DISCUSSION}

The dc motor parameters and its specific values are given in the table 1 it is standard values according to its constaints the research were carried out. To the object wise analysis of parameter and comparision were taken in matlab simulation.

TABLE I. Units for Magnetic Properties

\begin{tabular}{|l|l|}
\hline \multicolumn{1}{|c|}{ Parameters } & \multicolumn{1}{c|}{ Values } \\
\hline armature resistance & $2.58 \mathrm{Ohms}$ \\
\hline inductance & $0.028 \mathrm{H}$ \\
\hline field resistance & $281.3 \mathrm{Ohms}$ \\
\hline inductance & $151 \mathrm{Henry}$ \\
\hline $\begin{array}{l}\text { mutual inductance (MI) } \\
\text { field-armature }\end{array}$ & $0.94 \mathrm{Ohms}$ \\
\hline inertia & $0.022 \mathrm{~J}\left(\mathrm{k} \mathrm{g} \mathrm{m}^{2}\right)$ \\
\hline $\begin{array}{l}\text { coefficient of viscous } \\
\text { friction }\end{array}$ & $0.0029\left(\mathrm{~N} \mathrm{~m} \mathrm{~s}^{2}\right.$ \\
\hline friction torque coulomb & $0.51(\mathrm{~N} \mathrm{~m})$ \\
\hline initial field current & 1 \\
\hline initial speed & $0 \mathrm{rad} / \mathrm{sec}$ \\
\hline
\end{tabular}

\section{A. Simulation model in Matlab DC Motor}

Table 1 shows the parameters of SEDCM. By applying these values in Matlab model in figure 1 is formed to certain points to monitor the results.

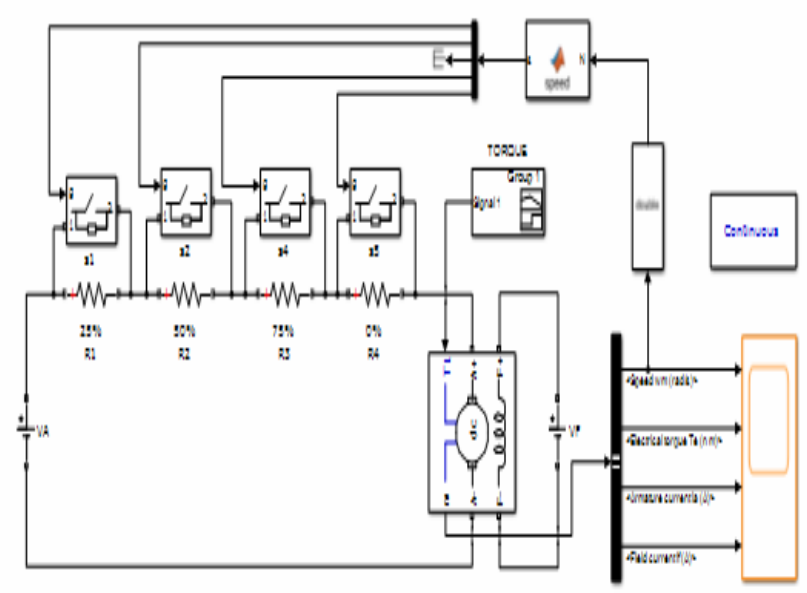

Fig. 1. SEDCM Matlab Model

When figure 2 is investigated and shows that armature current raises to $75 \mathrm{~A}$ in a few $1 / 1000 \mathrm{secs}$ and after $1 \mathrm{sec}$, it obtains stable and gets value $8 \mathrm{~A}$. Produced torque concurrently with armature current rise at desirable $70 \mathrm{Nm}$ in a few $1 / 1000$ secs and after $1 \mathrm{sec}$, it acquires steady and obtains $24.4 \mathrm{Nm}$.
Figure 3 illustrates that the motor speed reaches about 190 $\mathrm{rad} / \mathrm{s}$ in a 1/1000 sec and it brings stable after $0.03 \mathrm{sec}$.

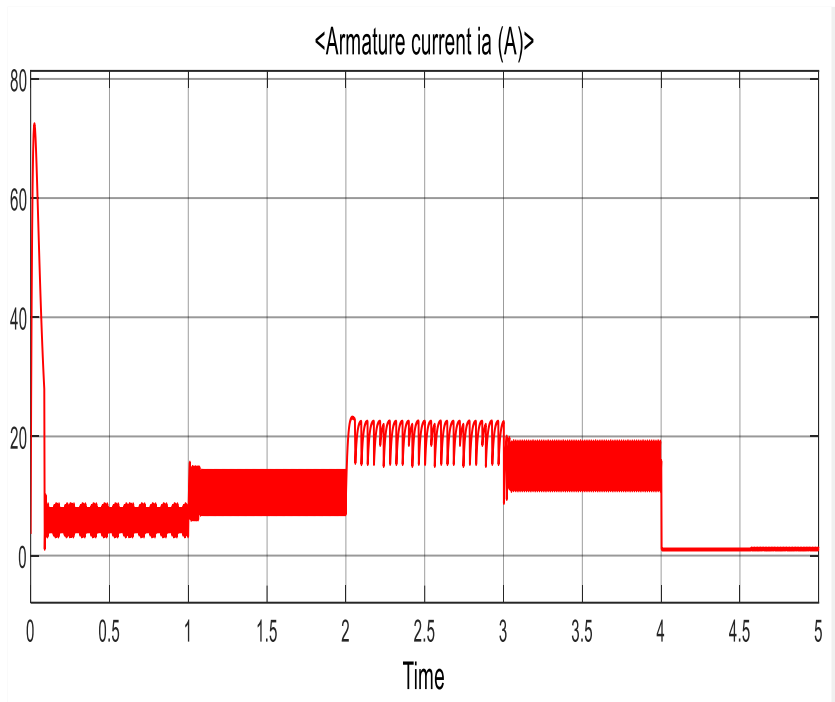

Fig. 2. Graph of Armature Current vs Time of SEDCM

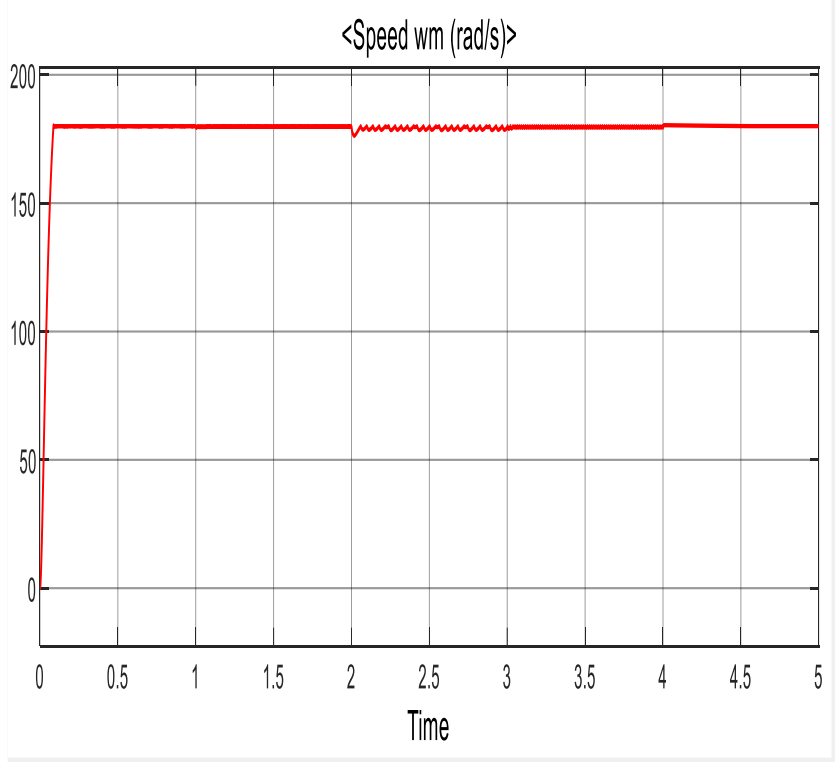

Fig. 3. Graphs of speed vs time of SEDCM

\section{B. Simulation model of PI for SEDCM}

PI controller based Model for SEDCM is shown in figure 4. PI controller is a combination of proportional controller $(\mathrm{P})$ and integral controller (I). The output of the current loop is fed first compare with the reference armature current the error signal is then deliver to a PI controller. The output of the PI controller is a fringing angle that is used to control the voltage for phase controlled rectifier. Figure 5 depicts motor achieve the desired speed 1500 in $0.4 \mathrm{sec}$, at the beginning motor with PI has overshoot 0.6 percentage which unacceptable. If the input voltage is fixed to a certain level that means the controller requirement of voltage more than a certain level, it means this not satisfy the result. 


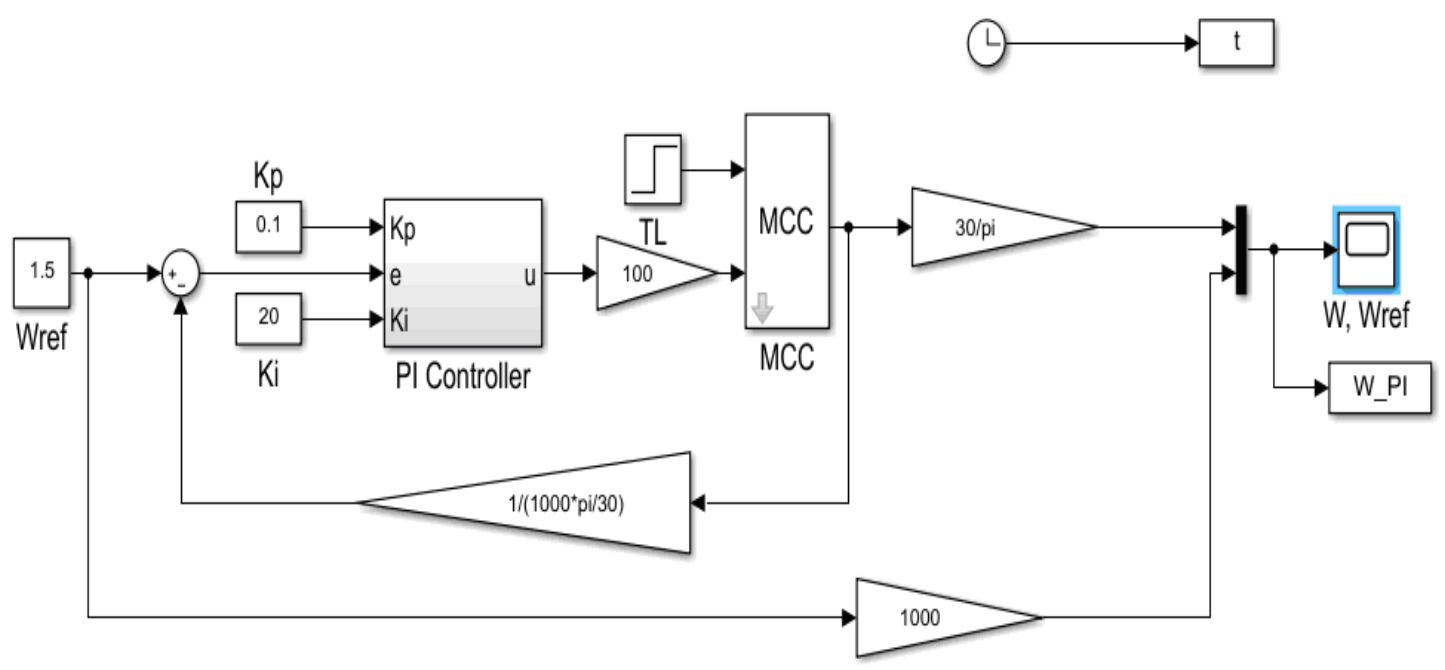

Fig. 4. PI-based Matlab model of SEDCM

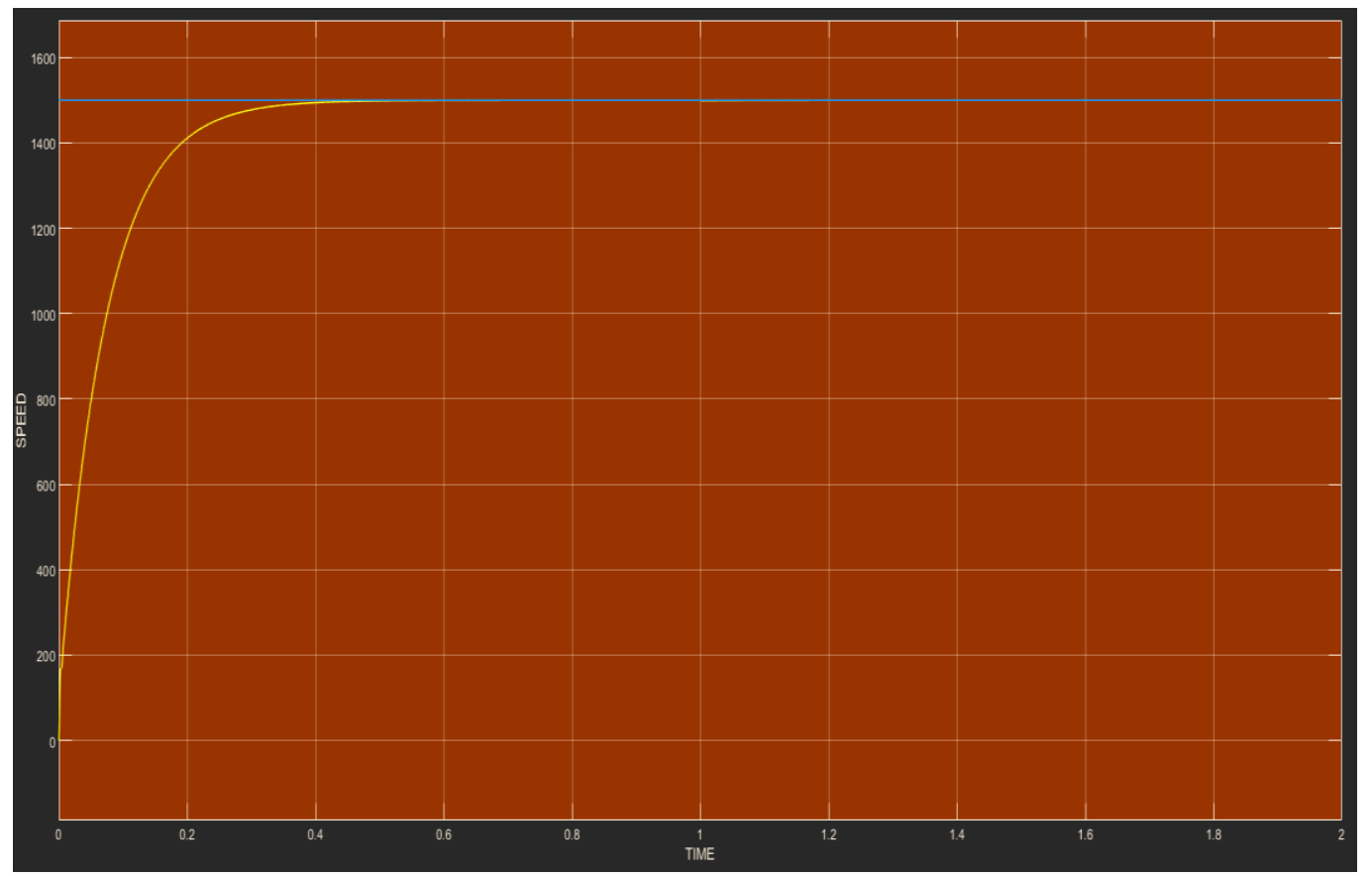

Fig. 5. Speed vs time response of SEDCM with PI Controller

\section{Simulation model of FLC for SEDCM}

In designed model the two inputs for Fuzzy Logic is change in current error and current error and its output is firing angle for phase controlled rectifier for controlling of separately excited DC motor.Acknowledge Fuzzy speed control system, where the input signals of PI are $\mathrm{kp}$ and ki and the output is firing angle reference are Fuzzed by selecting corresponding member ship functions to each signal. 


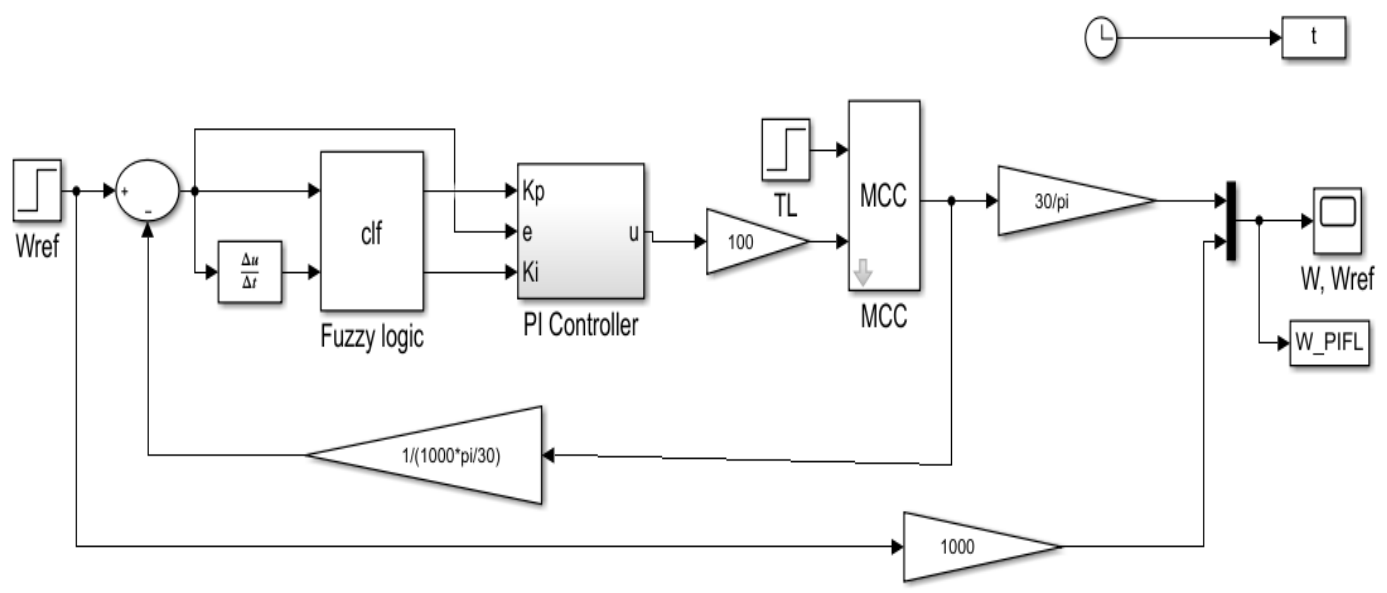

Fig. 6. PI and FLC based Matlab Model of SEDCM

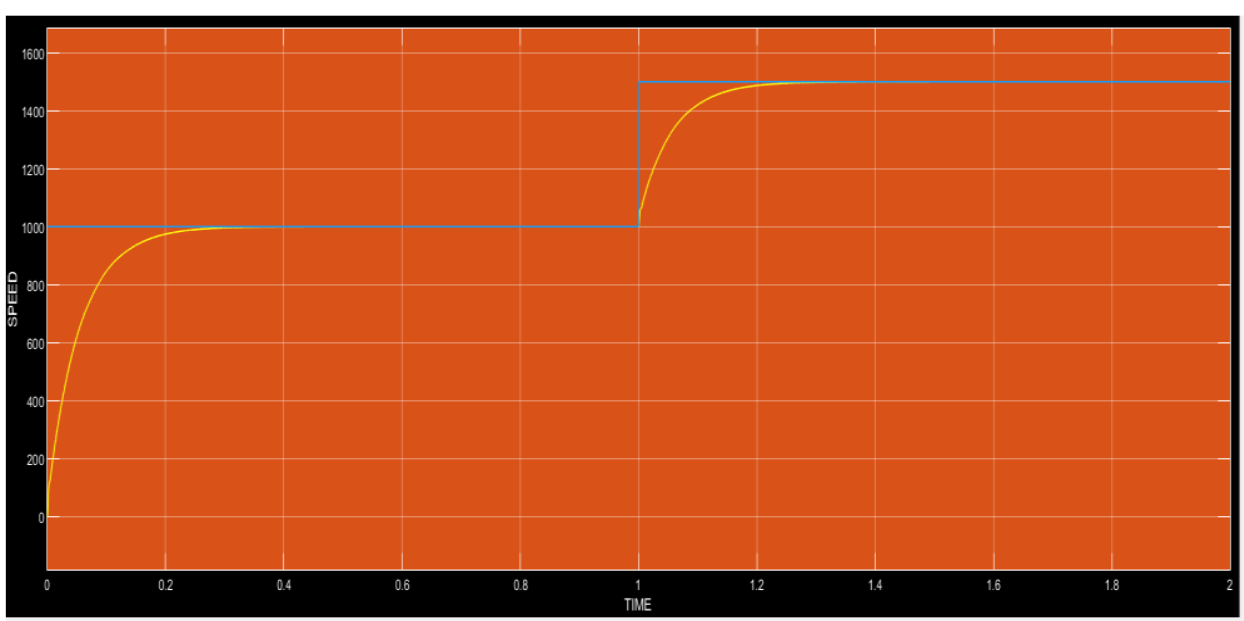

Fig. 7. PI and FLC based Matlab Model of SEDCM

Figure 7 shows the graph comparative analysis between PI and Fuzzy with time. The speed of SEDCM with fuzzy increase 0 to 1000 in $0.3 \mathrm{sec}$ unstable after it gets stable. From 1 to $1.2 \mathrm{sec}$ it is unstable with PI Controller after it gets stable and the speed of SEDCM is controlled.

\section{CONCLUSION}

This work has examined the basics of SEDCM and discussed the advantages of the fuzzy controller over PI

\section{REFERENCES}

[1] T. K. Trong, T. N, "The control structure for DC motor based on the flatness control", International Journal of Power Electronics and Drive Systems, vol. 8, no. 4, pp. 1814, 2017.

[2] B. Abdelhak, and B. Bachir, "A High gain observer based sensorless nonlinear control of induction machine", International Journal of Power Electronics and Drive Systems, vol. 5, no. 3, 305, 2015.

[3] R. Gunabalan, and V. Subbiah, "Speed Sensorless Vector Control of Induction Motor Drive with PI and Fuzzy controllers with their suitable parameters. Also, the sp`eed response graphs of DC motors using PI and Fuzzy controllers are successfully simulated in MATLAB R2019a and their speed responses concerning time are compared. Based on this comparative study and analysis, finally, from Figure 5 and Figure 7, it is clearly showing that the Fuzzy controller is much efficient in performance over PI controller for the speed of separately excited DC motors.

[4] Controller", International Journal of Power Electronics and Drive Systems, vol. 5, no. 3, 315, 2015.

[5] J. S. Park, and K. D. Lee, "Design and Implementation of BLDC Motor with Integrated Drive Circuit", International Journal of Power Electronics and Drive Systems (IJPEDS), vol. 8, no. 3, pp. 1109-1116, 2017.

[6] A. Hughes, and B. Drury, "Electric Motors and drives: fundamentals, types and applications," Newnes, 2013.

[7] M. A. Koondhar, A. K. Junejo, A. S. Saand, M. U. Keerio, "Speed Control of DC Series Motor with Conventional and PLC Techniques", Information Technology \& Electrical Engineering, vol. 5, no. 4, pp. 21- 26, 2016. 
[8] M. Prabha, and D. Menka,"Speed Control of DC Motor A Review", International Journal of Engineering Sciences \& Research Technology, pp. 298-305, 2015.

[9] M. A. Koondhar, A. A. Malak, M. A. Koondhar, I. A. Channa, "Experimental based Comparative Analysis and Characteristics of DC Series Motor by using Different Techniques", Sukkur IBA Journal of Emerging Technologies, vol. 3, no. 1, pp. 1-15, 2020.

[10] S. K. Suman, and V. K. Giri, "Genetic Algorithms Techniques Based Optimal PID Tuning For Speed Control of DC Motor", American Journal of Engineering and Technology Management, vol.1, no. 4, pp. 59-64, 2016.

[11] O. Akar, U. K. Terzi, and O. Ozgonenel, “A New Speed Control Technique for a Separately Excited Direct Current Motor by PID Controller", Balkan Journal of Electrical \& Computer Engineering, 6, pp. 12-17, 2018.

[12] M. A.. Ibrahim, A. N. Hamoodi, and B. M. Salih, "PI controller for DC motor speed realized with simulink and practical measurements", International Journal of Power Electronics and Drive System, vol. 11, no. 1, pp. 119-126, 2020.

[13] R. Nagarajan, et al., "Chopper fed speed control of DC motor using PI controller", Journal of Electrical and Electronics Engineering (IOSR-JEEE), vol. 11, no. 3, pp. 65-69, 2016.

[14] U. Kumar, and D. Dohare, "Separately excited DC motor speed control of using various tuning conventional controller", International Research Journal of Engineering and Technology, vol. 02, no. 08, 2015.

[15]R. Nagarajan, et al., "Chopper Fed Speed Control of DC Motor Using PI Controller", IOSR Journal of Electrical and Electronics Engineering (IOSR-JEEE), vol. 11, no. 3, pp. 65-69, 2016.

[16] V. M. V. Rao, "Performance analysis of speed control of DC motor using P, PI, PD and PID controllers", International Journal of Engineering Research \& Technology (IJERT), vol. 2, no. 5, 2013.

[17] R. Nagarajan, et al., "Implementation of chopper fed speed control of separately excited DC motor using PI controller", International Journal of Engineering And Computer Science, vol. 6, no. 3, pp. 20631-20633, 2017.

[18] A. Ahmed, et al., "Comparative study of speed control of DC motor using PI, IP, and fuzzy controller", International Journal of Advanced Research in Computer and Communication Engineering, vol. 2, no. 7, 2013.

[19] Y. A. Almatheel, and A. Abdelrahman, "Speed Control of DC Motor Using Fuzzy Logic Controller", In IEEE International Conference on Communication, Control, Computing and Electronics Engineering, Khartoum, Sudan, pp. 1-8, 2017.

[20] M. A. Ahmad, and P. Rai, "Speed control of a DC motor using Controllers", Automation, Control and Intelligent Systems, vol. 2, no. 6-1, pp. 1-9, 2014.

[21] J. R. Rashed, "Simulation of Speed Control for Separately Excited DC Motor Utilizing Fuzzy Logic Controller", University of Thi-Qar Journal for Engineering Sciences, 10(1), pp. 141-146, 2019.

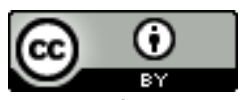

Journal of Applied and Emerging

Sciences by BUITEMS is licensed under a Creative Commons Attribution 4.0 International License. 